\title{
Biorefinery cascade processing for creating added value on tomato industrial by-products from Tunisia
}

Mouna Kehili', Lisa Marie Schmidt ${ }^{2}$, Wienke Reynolds ${ }^{3}$, Ayachi Zammel ${ }^{4}$, Carsten Zetz| $\left.\right|^{3}, \mid$ rina Smirnova ${ }^{3}$, Noureddine Allouche ${ }^{5^{*}}$ and Sami Sayadi ${ }^{1}$

\begin{abstract}
Background: In today's consumer perception of industrial processes and food production, aspects like food quality, human health, environmental safety, and energy security have become the keywords. Therefore, much effort has been extended toward adding value to biowastes of agri-food industries through biorefinery processing approaches. This study focused, for the first time, on the valorization of tomato by-products of a Tunisian industry for the recovery of value-added compounds using biorefinery cascade processing.

Results: The process integrated supercritical $\mathrm{CO}_{2}$ extraction of carotenoids within the oil fractions from tomato seeds (TS) and tomato peels (TP), followed by a batch isolation of protein from the residues. The remaining lignocellulosic matter from both fractions was then submitted to a liquid hot water (LHW) hydrolysis. Supercritical $\mathrm{CO}_{2}$ experiments extracted $5.79 \%$ oleoresin, $410.53 \mathrm{mg}$ lycopene $/ \mathrm{kg}$, and $31.38 \mathrm{mg} \beta$-carotene $/ \mathrm{kg}$ from TP and 26.29\% oil, $27.84 \mathrm{mg}$ lycopene $/ \mathrm{kg}$, and $5.25 \mathrm{mg} \beta$-carotene/ $\mathrm{kg}$ from TS, on dry weights. Protein extraction yields, nearing $30 \%$ of the initial protein contents equal to $13.28 \%$ in TP and $39.26 \%$ in TS, revealed that TP and TS are a rich source of essential amino acids. LHW treatment run at $120-200{ }^{\circ} \mathrm{C}, 50$ bar for 30 min showed that a temperature of $160^{\circ} \mathrm{C}$ was the most convenient for cellulose and hemicellulose hydrolysis from TP and TS, while keeping the degradation products low.

Conclusions: Results indicated that tomato by-products are not only a green source of lycopene-rich oleoresin and tomato seed oil (TSO) and of protein with good nutritional quality but also a source of lignocellulosic matter with potential for bioethanol production. This study would provide an important reference for the concept and the feasibility of the cascade fractionation of valuable compounds from tomato industrial by-products.
\end{abstract}

Keywords: Biorefinery, Tomato industrial by-products, $\mathrm{SC}-\mathrm{CO}_{2}$ extraction, Carotenoids, Oil, Protein isolation, Liquid hot water hydrolysis, Lignocellulose

\section{Background}

The biorefinery concept is defined as an approach for the generation of value-added products such as biochemicals, biofuels, heat, and electricity from renewable energy sources and particularly from biomass [1-3]. Being available in large quantities and non-competitive with the food industry, the agro-industrial by-products become more and more interesting as raw materials for

\footnotetext{
*Correspondence: noureddineallouche@yahoo.fr

${ }^{5}$ Laboratory of Chemistry of Natural Substances UR11-ES74, Faculty of Sciences of Sfax, University of Sfax, PO Box 1171, 3000 Sfax, Tunisia Full list of author information is available at the end of the article
}

such refineries [4]. In the context of tomato agriculture, worldwide, million tons are industrially processed yearly resulting in large amounts of residues that are estimated around $4 \%$ of the total processed tomatoes $[5,6]$. In the last decade, Tunisia was ranked number 9 worldwide for the industrial transformation of tomatoes, with a rate of 36,000 tons of raw tomatoes per day within the summer season. Consequently, high quantities of by-products, ranging between 20,000 and 30,000 tons, were disposed from the Tunisian tomato industry per year, with 56 and $44 \%$ being the respective proportions of tomato peels and seeds. 
Since these residues contain a large valuable fraction, they could be further treated at the industrial site for the production of bioactive compounds or biofuels, increasing the bioeconomy and solving the problem of pollution connected with tomato processing. Indeed, tomato peels were reported to contain, on dry basis, $14-20 \%$ protein $[6,7], 40-74 \%$ lignocellulosic material [6-8], and 3-5\% oleoresin, being the oil fraction from tomato peels $[9,10]$. Besides, tomato seeds were shown to contain $20-40 \%$ protein [11, 12], 35-50\% lignocellulosic material [7, 13], and $18-37 \%$ oil $[14,15]$. Nevertheless, currently, valorization of tomato peels has attracted little interest, since they are mostly considered for the extraction of carotenoids, especially lycopene [6], while tomato seeds have attracted very limited attention so far. Effectively, there was a current upsurge concerning carotenoid extraction from tomato peels regarding their significant role in human health by acting as biological antioxidants [16]. In this context, tomatoes were shown to be the major source of dietary lycopene whose concentrations vary from 430 to $2950 \mathrm{mg} / \mathrm{kg}$, on dry basis, with tomato peels containing about five times more lycopene than tomato pulp [17]. Recently, supercritical $\mathrm{CO}_{2}\left(\mathrm{SC}-\mathrm{CO}_{2}\right)$ has been favored for the extraction of lycopene. Indeed, this green and safe technology is suitable for the recovery of lipophilic substances, e.g., carotenoids, and lipids from numerous plant matrices [18]. Yet, regarding literature, few papers have recently suggested other valorization pathways of tomato by-products such as biofuel production or as a source of oil, polysaccharides, and protein. For instance, Sarkar and Kaul [11] identified a pilot plant setup to extract tomato seeds protein toward its commercial application as a functional additive in food formulations. Additionally, the study by Rossini et al. [19], performed on tomato manufacturing residues, suggested the use of tomato peels for combustion and tomato seeds for mechanical oil extraction. Moreover, based on the fiber analysis of tomato industrial peel by-product, Toscano et al. [8] showed that hemicellulose, cellulose, and lignin dry mass fractions corresponded to 4.8, 22.5, and $46.9 \%$, respectively. This structural composition encouraged Toscano et al. [8] to use this processing residue for the production of a solid biofuel with energy properties similar to those of coal through a torrefaction treatment. Besides, Del Campo et al. [20] revealed that tomato residues could be potential feedstocks for ethanol production not only because of their low cost and high availability but also because of their considerable amount of sugars. In fact, Del Campo et al. [20] found between 40.3 and $50.2 \%$ of soluble sugars by weight in the hydrolysate after hydrothermal treatment of tomato residues at temperatures from 100 to $130{ }^{\circ} \mathrm{C}$ and reaction times from 5 to $30 \mathrm{~min}$.
Practically, to be effectively used as a raw material in biorefinery for biofuel production, tomato by-products need to be firstly hydrolyzed to fermentable sugars [2, 3 , 21]. Recent innovations about lignocellulosic biomass hydrolysis include acid or base treatments, which are not yet satisfactory because of the ecological waste issues [22, 23]. Hydrolysis with hemicellulolytic and cellulolytic enzymes had also been commonly used for lignocellulose degradation [2, 24]. However, enzymatic hydrolysis is time consuming and is not enough to break down the hemicellulose and cellulose complex structures to simple sugars $[2,25,26]$. Interestingly, the hydrolysis with liquid hot water (LHW), a physicochemical process using pressurized water, is picking up an expanding consideration as an environmentally friendly technique. Effectively, LHW has an extensive variety of applications, such as extraction, hydrolysis, and wet oxidation of organic compounds $[4,25,27]$.

Despite the advanced literature, Scoma et al. [28] and Vardanega et al. [29] revealed that reports on multi-target second-generation biorefinery of tomato residues are still very few in literature. Therefore, this paper focuses on using a consecutive biorefinery approach to investigate the potential of tomato industrial by-products of a Tunisian industry for the recovery of value-added products including oleoresin, oil, carotenoids, protein, sugar, and lignin. In a first step, carotenoids were extracted within the lipid fraction, oleoresin from tomato peels and tomato seed oil, using $\mathrm{SC}-\mathrm{CO}_{2}$. The residues from the $\mathrm{SC}-\mathrm{CO}_{2}$ extraction step were then submitted to batch protein extraction. LHW hydrolysis was applied for the treatment of solid residues, recovered after $\mathrm{SC}-\mathrm{CO}_{2}$ and protein extraction for the recovery of hemicellulose sugars. Although the integration of all thermal separation processes in a kind of "one stop unit" is feasible, in this work, it has been decided that the bespoken cascade still contains some transfer interfaces between the different unit operations, for research and analytical purposes. Moreover, for all process steps, the most important process parameters were investigated based on preliminary results. Then, the effect of preliminary protein and oil extraction on LHW hydrolysis was investigated.

With regard to the scale-up feasibility of the processes requiring high pressure, it is noteworthy that the supercritical and compressed fluid extractions have found their origin in the industrial petrorefinery in the 1950s through the Solexol ${ }^{\circledR}$ and the $\operatorname{ROSE}^{\circledR}$ (residuum oil supercritical extraction) processes [30, 31]. Recently, these technologies have been also applied in large scale in food and pharmaceutical industries, as the benefits of the process are overweighting the investment costs either in the case of the high-value extracts, e.g., carotenoids and phytopharmaceuticals, or in the case of added consumer 
value on the residue, e.g., decaffeinated coffee and defatted oil crops for cattle feed. Interestingly, a reproducible trend for cost statements was found in the study by Brunner [32] that reported process costs of approximatively 500-1000 EUR/ton for the treatment of an annual amount of 30,000 tons of solid biomass. In the same way, high-pressure techniques for hot water hydrolysis and steam explosion are nowadays applied in second-generation biorefineries at least in large industrial pilot scale, as can be seen in the processes of Clariant Sunliquid ${ }^{\circledR}$ (Germany), Proesa ${ }^{\circledR}$ (Italy), and Inbicon ${ }^{\circledR}$ (Denmark).

\section{Methods}

\section{Feedstock}

Tomato peels and seeds were recovered from a processing plant of peeled tomato, located in Siliana, Tunisia. The residues from tomato processing were dried under sunlight until a dry matter content of $95 \pm 2 \%$. The dried residue, consisting of $35 \%$ of tomato seeds and $65 \%$ of tomato peels on dry basis, was separated using manual sieves, then ground using a conventional grinder to a maximum particle size of $300 \mu \mathrm{m}$, and kept at $-20{ }^{\circ} \mathrm{C}$ until further use.

\section{Chemicals}

Lycopene, $\beta$-carotene, O-phthaldialdehyde (OPA), hexane, and hydrochloric acid were purchased from Sigma Chemical Co. (Sigma-Aldrich Company, St. Louis, MO, USA). Citric acid monohydrate, sodium hydroxide, acetonitrile, dichloromethane, methanol, and sulfuric acid were purchased from Carl Roth GmbH (Karlsruhe, Germany). Ethyl acetate and calcium carbonate were obtained from Merck (Darmstadt, Germany), and disodium phosphate was purchased from Fluka (Buchs, Switzerland). Carbon dioxide (99.5\%) purchased from Yara/ Praxair GmbH (Neuwied, Germany) was used for the supercritical extraction experiments. Nitrogen (99.95\%) from Westfalen AG (Münster, Germany) was used for maintaining pressure in the filling process with liquid hot water.

\section{Steps of biorefinery cascade processing Supercritical $\mathrm{CO}_{2}$ extraction}

An analytical and research Spe-ed SFE-2/4 unit (Applied Separations, Allentown, PA, USA) was used. The apparatus was equipped with a stainless steel extraction column (50 $\mathrm{cm}^{3}$ of capacity), a back pressure regulator, a cooling unit, a high-pressure pump for $\mathrm{CO}_{2}$, and a $\mathrm{CO}_{2}$ flow meter. Liquid $\mathrm{CO}_{2}$ was passed through a cooling unit and compressed to the operating pressure by a high-pressure pump. Compressed $\mathrm{CO}_{2}$ was fed continuously into the extractor maintained at the operating pressure and temperature. $10 \mathrm{~g}$ of ground tomato biomass (peels or seeds) was loaded into the extraction vessel. The $\mathrm{SC}-\mathrm{CO}_{2}$ extraction was run under $80{ }^{\circ} \mathrm{C}, 400 \mathrm{bar}$, and $4 \mathrm{~g} \mathrm{CO}_{2} /$ $\min$ for $2 \mathrm{~h}$. At the outlet of the extractor, the fluid was expanded to the atmospheric pressure and the carried solute was collected, each $30 \mathrm{~min}$, in a preweighed glass vial. The different glass vials were weighed to determine the amount of oleoresin and oil extracted from tomato peels and seeds. The vials were then kept at $-20{ }^{\circ} \mathrm{C}$ for further analysis of the carotenoid contents (lycopene and $\beta$-carotene) using high-performance liquid chromatography (HPLC). The supercritical fluid extraction (SFE) residues of peels and seeds were weighed and considered for the next step of protein batch extraction. This step was repeated twice under the same set of conditions.

\section{Protein extraction}

In this step, batch protein extraction was performed according to the protocol applied by Gairola [33], who extracted proteins from brewers' spent grains, with some modifications. A quantity of $10 \mathrm{~g}$ of SFE residues was added to $200 \mathrm{~mL}$ of $\mathrm{NaOH}(0.05 \mathrm{M})$ and maintained at $90{ }^{\circ} \mathrm{C}$ for $30 \mathrm{~min}$ under magnetic stirring at $700 \mathrm{rpm}$. Once cooled down, this solution was centrifuged at $4500 \mathrm{rpm}$, for $1 \mathrm{~h}$ at $25^{\circ} \mathrm{C}$. The raffinate phase, separated solid, was subjected to the next step of LHW hydrolysis, and the supernatant was considered for protein precipitation by decreasing $\mathrm{pH}$ to a value of $4 \pm 0.1$ with citric acid $(0.5 \mathrm{M})$ solution. The mixture was centrifuged again at $4500 \mathrm{rpm}$, for $1 \mathrm{~h}$ at $25^{\circ} \mathrm{C}$, and the raffinate was considered as the final protein extract. For comparison, protein extraction was similarly carried out starting from raw samples of tomato peels and seeds, not submitted to a previous SFE step. Protein extraction was performed twice starting from raw and pretreated residues.

\section{Liquid Hot Water hydrolysis}

LHW hydrolysis was carried out in stainless steel reactors with a volume of $45 \mathrm{~mL}$ each (High Pressure Reactor BR-25, Berghof, Eningen, Germany). The temperature inside the reaction mixture was controlled over the heating jackets as described also by Gairola and Smirnova [34]. In each reactor vessel, $0.6 \mathrm{~g}$ of tomato biomass (dry matter) was adjusted to $30 \mathrm{~g}$ with distilled water inside a polytetrafluoroethylene (PTFE) cartridge. Nitrogen was used to pressurize the reactor to 50 bar. The reaction was carried out for $30 \mathrm{~min}$ at three different temperatures $\left(120,160\right.$, and $\left.200{ }^{\circ} \mathrm{C}\right)$. The reaction was stopped using an iced water bath. Kazan et al. [2] and Mohan et al. [25] suggested similar LHW operating time for optimum olive pomace and bamboo hydrolysis. Afterwards, the hydrolysate and the solid residue were separated by centrifugation at $4500 \mathrm{rpm}$ and $25^{\circ} \mathrm{C}$ for $1 \mathrm{~h}$. The solid fraction was dried at $60{ }^{\circ} \mathrm{C}$ prior to the compositional analysis of their 
lignin, cellulose, and hemicellulose contents [26]. The supernatant was collected and analyzed for its composition in organic acids, sugars monomers, and oligomers. For comparison, LHW hydrolysis was similarly carried out starting from raw samples of tomato peels and seeds which were not submitted to a previous SFE and protein extraction steps. Each experiment was carried out in duplicate.

\section{Analytical methods \\ Initial lipid contents in tomato by-products}

$5 \mathrm{~g}$ of dry biomass and $200 \mathrm{~mL}$ of hexane were used for the extraction of the maximum oleoresin and oil contents in tomato peels and seeds using Soxhlet extraction for $12 \mathrm{~h}$ [35]. During extraction, the Soxhlet extractor was covered with an aluminum foil to prevent oxidation and degradation of the valuable carotenoids. The Soxhlet extraction was carried out in triplicate and the extracts were dried using a rotary evaporator. The lipid fraction mass, extracted from both samples, was determined gravimetrically and considered as $100 \%$ extraction yields of oleoresin and oil. These total lipid fractions, oleoresin from tomato peels and tomato seed oil, were dissolved in ethyl acetate, filtrated using $0.22-\mu \mathrm{m}$ hydrophobic PTFE membrane filters, and analyzed for their total lycopene and $\beta$-carotene contents using HPLC as detailed below [35].

\section{Lycopene and $\beta$-carotene quantification}

The obtained extracts from tomato peels and seeds, oleoresin and tomato seed oil, respectively, were analyzed using HPLC for their lycopene and $\beta$-carotene contents. SFE extracts, dissolved in ethyl acetate, were analyzed using a Ginkotek HPLC system equipped with an Agilent eclipse XDB-C18 column $(5 \mu \mathrm{m} ; 4.6 \mathrm{~mm} \times 150 \mathrm{~mm})$ and a UV-Vis detector (SPD-GAV). An isocratic mode was applied for the elution of carotenoids using acetonitrile/ dichloromethane mixture $(75: 25 ; \mathrm{v} / \mathrm{v})$. Chromatographic separation of the samples was performed at a constant flow rate of $1.5 \mathrm{~mL} / \mathrm{min}$ and the absorption wavelength was set at $470 \mathrm{~nm}$. In the extracts, lycopene and $\beta$-carotene were identified and quantified by comparing their retention times and peak areas with their respective standards analyzed under the same conditions [17]. All samples were analyzed in duplicate.

\section{Protein analysis}

The protein content was calculated based on the nitrogen content estimated with Kjeldahl method, for the solid fractions, multiplied by the specific factors equal to 6.67 for tomato peels and 6.46 for tomato seeds. Herein, the specific factors were determined based on the amino acid analysis of the protein extracts from both tomato residues. Since we aimed to determine the mass balance of protein within the different fractions after the protein extraction step, the protein content in the aqueous fraction was determined using the Analytic Jena multi N/C 3100 instrument (Jena, Germany). Besides, the composition of the protein extracts in amino acids was assessed after hydrolysis with $6 \mathrm{M} \mathrm{HCL}$ at $115{ }^{\circ} \mathrm{C}$ for $16 \mathrm{~h}$, derivatization with $\mathrm{O}$-phthaldialdehyde (OPA), and analysis with reversed-phase HPLC. The HPLC was equipped with a ZORBAX Eclipse C18 column $(3.5 \mu \mathrm{m} ; 4.6 \mathrm{~mm} \times 150 \mathrm{~mm})$ and a fluorescence detector (Jasco FP1520) connected to a Chromeleon data system (Thermo Scientific). The temperature of the HPLC column was maintained at $21{ }^{\circ} \mathrm{C}$. Gradient elution was applied using $\mathrm{Na}_{2} \mathrm{HPO}_{4}$ buffer $(0.04 \mathrm{M}), \mathrm{pH} 7.8$, and a mixture of acetonitrile/methanol/water, 45/45/10 (v/v), at a flow rate of $2 \mathrm{~mL} / \mathrm{min}$.

The nutritional quality of the protein from tomato residues was estimated based on two parameters: amino acid scoring pattern and protein efficiency ratio (PER) according to Sarkar and Kaul [11]. The amino acid score was calculated by dividing the content of each amino acid by a reference amino acid pattern of a protein recognized for the nutrition of preschool children (1-2 years old) [36]. Moreover, the PER was calculated as an average of the following three equations with amino acids contents measured as $\mathrm{g} / 100 \mathrm{~g}$ protein [11]:

$$
\begin{aligned}
\mathrm{PER}= & -0.684+0.456 \times(\mathrm{Leu})-0.047 \times(\text { Pro }) \\
\mathrm{PER}= & -0.468+0.454 \times(\mathrm{Leu})-0.105 \times(\mathrm{Tyr}) \\
\mathrm{PER}= & -1.816+0.435 \times(\text { Met })+0.78 \times(\text { Leu }) \\
& +0.211 \times(\text { His })-0.944 \times(\mathrm{Tyr}) .
\end{aligned}
$$

\section{Liquid fraction analysis after liquid hot water treatment}

After LHW treatment, the liquid fractions were analyzed for their sugar monomer and oligomer contents as well as sugar degradation products such as furfural, hydroxymethylfurfural (HMF), and organic acids using a HPLC system (1200 Agilent Technologies) with refraction index detection (1100 Agilent Technologies). The HPLC analysis was performed at $40{ }^{\circ} \mathrm{C}$ using dilute $\mathrm{H}_{2} \mathrm{SO}_{4}(0.025 \%)$ as an eluent at a flow rate of $0.3 \mathrm{~mL} / \mathrm{min}$. Analytical hydrolysis was carried out for $60 \mathrm{~min}$ at $121{ }^{\circ} \mathrm{C}$ with $4 \% \mathrm{H}_{2} \mathrm{SO}_{4}$. The samples were neutralized with $\mathrm{CaCO}_{3}$, centrifuged, and analyzed again for their sugar content using HPLC. For calculation, xylose, arabinose, galactose, mannose, rhamnose, and lactose were assigned to the hemicellulose fraction, whereas the complete amount of glucose, fructose, and cellobiose was considered as cellulose [25, 37]. Additionally, as part of the hexoses and pentoses are converted to other by-products, these sugar transformation by-products were calculated as the percentage of the initial amount of hemicellulose and cellulose contained in the solid sample submitted to the LHW experiment. The 
sugar transformation by-products include HMF, furfural, levulinic acid, formic acid, and lactic acid.

\section{Solid fraction analysis after liquid hot water treatment}

For acid-insoluble lignin determination and sugar analysis, the solid samples were treated using a two-step acid hydrolysis [37, 38]. The biomass was mixed with $72 \%$ $\mathrm{H}_{2} \mathrm{SO}_{4}(\mathrm{w} / \mathrm{w})$ and hydrolyzed for $1 \mathrm{~h}$. Subsequently, water was added for diluting the $\mathrm{H}_{2} \mathrm{SO}_{4}$ solution to $4 \%$ and the sample was boiled for $40 \mathrm{~min}$ [2]. The solid residue was filtered, dried, and weighed to determine the acid-insoluble lignin content. The sugars were quantified within the hydrolysates by HPLC.

\section{Results and discussion}

\section{Supercritical $\mathrm{CO}_{2}$ extraction}

The first step in the biorefinery cascade approach aimed to extract the carotenoids within oleoresin and oil from ground tomato peels (TP) and seeds (TS), respectively, using supercritical $\mathrm{CO}_{2}$. Figure 1a shows the profile of the extraction yields of oleoresin from TP and oil from TS expressed as the percentage of the respective cumulative extracted mass to the initial dry mass, over time. After $120 \mathrm{~min}$ of $\mathrm{SC}-\mathrm{CO}_{2}$ extraction, about 95.07 and $98.61 \%$ of the initial oleoresin and oil contents in TP and TS were recovered, respectively, relating to the extraction of $5.79 \pm 1.33 \%$ oleoresin from dry TP and $26.29 \pm 3.30 \%$ oil from dry TS.

In comparison with literature, the present result exhibits higher oleoresin extraction yield (95.07\%) than that of $31.78 \%$ found by López-Cervantes et al. [10] using ultrasound-assisted extraction of oleoresin from over-ripe tomato using acetone, with the original oleoresin content being equal to $4.50 \pm 0.10 \%$. Besides, the yield of tomato seed oil (TSO) extracted in the present study was found to be much higher compared to that found in the study of Eller et al. [39]. Actually, the latter research extracted $17.3 \%$ of TSO representing $75 \%$ of the maximum extractable oil from dry TS using $\mathrm{SC}-\mathrm{CO}_{2}$ at $80{ }^{\circ} \mathrm{C}, 552 \mathrm{bar}$, and a flow rate of $300 \mathrm{~g} / \mathrm{min}$ within an extraction cell holding $1.5 \mathrm{~kg}$ of ground TS. The difference between results can be attributed to the solvent-to-TS ratio that is equal to $0.4 \mathrm{~g} \mathrm{CO}_{2} /$ g.min in the present study, while that reported by Eller et al. [39] was equal to $0.2 \mathrm{~g} \mathrm{CO}_{2} / \mathrm{g}$.min. In fact, an increase in $\mathrm{CO}_{2}$ flow rate seemed to increase the mass transfer of the mediated solutes in $\mathrm{CO}_{2}$, enhancing their recovery yields [16].

Figure 1b summarizes the cumulative lycopene extraction yields from TP and TS using $\mathrm{SC}-\mathrm{CO}_{2}$. Actually, at the end of the extraction time, $410.53 \pm 35.12 \mathrm{mg}$ lycopene/ $\mathrm{kg}$ TP was extracted. This yield represents $60 \%$ of the initial lycopene amount equal to $684.23 \pm 19.21 \mathrm{mg} / \mathrm{kg}$ TP. The present result is comparable with that reported by
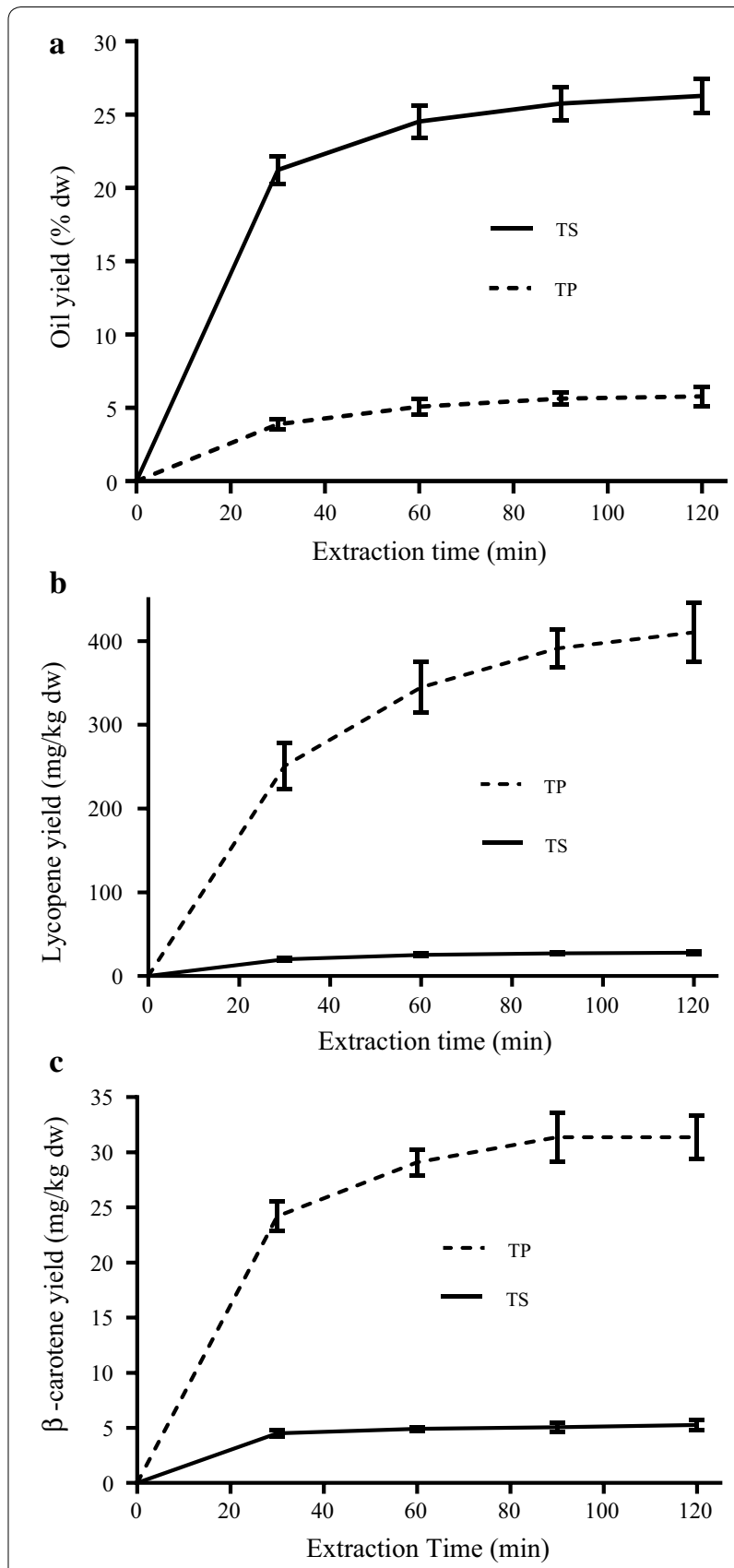

Fig. 1 Variation of oil (a), lycopene $(\mathbf{b})$, and $\beta$-carotene $(\mathbf{c})$ extraction yields from dry weights ( $d w$ ) of tomato peel (TP) and tomato seed (TS) by-products using $\mathrm{SC}-\mathrm{CO}_{2}$ at $400 \mathrm{bar}, 80^{\circ} \mathrm{C}$, and $4 \mathrm{~g} \mathrm{CO}_{2} / \mathrm{min}$ for 120 min using a batch of $10 \mathrm{~g}$ of biomass with $300 \mu \mathrm{m}$ particle size

Machmudah et al. [17] who reached a lycopene extraction yield of $56 \%$ of the initial lycopene amount, corresponding to $459.20 \mathrm{mg} / \mathrm{kg}$ of dry tomato by-product input. The latter study [17] used $\mathrm{SC}-\mathrm{CO}_{2}$ extraction in the presence of tomato peels/seeds ratio of $37 / 63$, run under $400 \mathrm{bar}, 90{ }^{\circ} \mathrm{C}$, and a $\mathrm{CO}_{2}$ flow rate of $4 \mathrm{mg} / \mathrm{min}$ 
for 180 min using $4 \mathrm{~g}$ of material. Besides, about $82.22 \%$ of the initial lycopene content in TS was recovered after $120 \mathrm{~min}$ of $\mathrm{SC}-\mathrm{CO}_{2}$ extraction, relating to the extraction of $27.84 \pm 1.33 \mathrm{mg}$ lycopene/ $\mathrm{kg}$ dry TS (Fig. 1b). Hence, the TSO recovered at the output of the $\mathrm{SC}-\mathrm{CO}_{2}$ extraction was rich in lycopene whose concentration was equal to $105.89 \pm 13.43 \mathrm{mg} / \mathrm{kg}$ TSO.

Furthermore, about 58.82 and $90 \%$ of the initial $\beta$-carotene contents in TP and TS were recovered after $120 \mathrm{~min}$ of $\mathrm{SC}-\mathrm{CO}_{2}$ extraction, relating to the extraction of $31.38 \pm 1.98$ and $5.25 \pm 0.48 \mathrm{mg} \beta$-carotene $/ \mathrm{kg}$ of dry TP and TS, respectively (Fig. 1c). As a result, the $\beta$-carotene content in TSO was about $19.97 \pm 1.80 \mathrm{mg} /$ $\mathrm{kg}$ TSO which is comparable with the value reported by Müller et al. [12]. Indeed, among the few studies interested in the content of carotenoids in TS and TSO, Müller et al. [12] found that TSO contained $95.60 \pm 3.60 \mathrm{mg}$ lycopene $/ \mathrm{kg}$ and $16.60 \pm 0.40 \mathrm{mg} \beta$-carotene $/ \mathrm{kg}$ TSO.

Obviously, the final extraction yields of lycopene and $\beta$-carotene are much higher starting from TS as compared to those from TP, more likely because of the high amount of oil in TS. Effectively, the oil content may have induced a co-solvent effect enhancing the solubility and the recovery yields of carotenoids that are highly lipophilic molecules [17]. Therewith, the major amount of the extracted oil and carotenoids from TP and TS, exceeding $60-85 \%$ of the final extracted amounts, were recovered during the first $30 \mathrm{~min}$ of the extraction time, in all cases (Fig. 1). Indeed, the short extraction time is one of the main promoting aspects of $\mathrm{SC}-\mathrm{CO}_{2}$ extraction reducing the processing costs while producing a safe and solvent-free extract [40].

In the same context, the study by Prado et al. [41] compared low-pressure solvent extraction (LPSE) with $\mathrm{SC}-\mathrm{CO}_{2}$ extraction of carotenoids from a large number of vegetable sources. The LPSE included the Soxhlet, agitation, homogenization, shaking, ultrasound-assisted extraction, and centrifugal extraction. In their review [41], they obviously revealed that a large margin of processing times can be considered for each extraction method depending on the raw material selected and all other operating parameters applied. Hence, none of the reviewed approaches can be rated as the best answer for every extractable compound and raw material. Nevertheless, a large number of studies suggested a positive trend toward using $\mathrm{SC}-\mathrm{CO}_{2}$ extraction for the recovery of carotenoids mainly regarding the growing restrictions imposed on the use of most organic solvents for the extraction of food products [41, 42]. Besides, the advantages of $\mathrm{SC}-\mathrm{CO}_{2}$ extraction over the conventional methods include the high diffusivity of compressed $\mathrm{CO}_{2}$ as well as the possibility and the ease of monitoring the fluid dynamics and the extraction kinetics through the variation of solvent velocity, for instance. Thus, the process costs and equipment characteristics can be set based on the cumulative extraction plots of a specific compound from a given material input, as highlighted by Del Valle et al. [43].

\section{Protein extraction}

Raw TP and TS as well as $\mathrm{SC}-\mathrm{CO}_{2}$-treated TP and TS residues were considered for protein quantification, extraction, and analysis. The initial protein content was equal to $13.28 \pm 3.21 \%$ in raw TP and $39.26 \pm 1.15 \%$ in raw TS, on dry basis. Comparably, Persia et al. [13] and Sarkar and Kaul [11] reported that the protein content in TS ranged between 24 and $40 \%$ on dry basis depending on the environmental and genetic varieties. Considering the pretreated tomato by-products with $\mathrm{SC}-\mathrm{CO}_{2}$, protein contents showed negligible difference with that of raw samples for both TP and TS. The protein extraction yields from pretreated TP and TS, expressed as the percentage of their respective initial protein contents, were $27.37 \pm 0.98 \%$ and $35.82 \pm 2.22 \%$. Starting from raw TP and TS, the protein extraction yields were comparable with those of pretreated samples. However, the protein concentration within the final protein extracts was much higher starting from pretreated TP and TS as compared to that from raw TP and TS. In fact, the protein fraction was $35.83 \pm 1.95 \%$ from pretreated TP and $80.90 \pm 2.56 \%$ from pretreated TS, while it was $27.41 \pm 2.13 \%$ from raw $\mathrm{TP}$ and $55.25 \pm 3.24 \%$ from TS, on dry protein extract basis. Hence, the defatting step using $\mathrm{SC}-\mathrm{CO}_{2}$ seemed to be useful for better purity of the protein isolates mainly for TS, probably because the fact of removing the lipid fraction from tomato by-products may have led to fewer impurities in the aqueous protein extracts. Likewise, Sarkar and Kaul [11] performed protein isolation from defatted tomato ground seeds (seed meal) by salt extraction. In this study [11], they revealed a higher yield of protein extract that was equal to $27.3 \%$ of dry tomato seed meal, representing $68.45 \%$ of the initial protein content, with a crude protein concentration of $91.66 \%$ in the protein isolate.

It is worth noting, based on the mass balance of protein, that around $15 \%$ of the initial protein amount was found within the supernatant after protein precipitation and that the major protein fraction, exceeding $50 \%$ of the initial protein amount, was recovered in the solid fraction after the first centrifuge of protein solution. This fact can be considered for further optimization of the protein recovery yield within the final extract using, for instance, a two-step protein extraction as suggested in the study by Zhang et al. [44]. Indeed, in this study [44], they provide a good reference for the optimization of critical parameters toward a cost-effective alkaline extraction of a high 
protein yield equal to $85 \%$ of the initial protein content in green tea residue, with a purity of $52 \%$.

The total amino acid profiles of the protein isolates from TP and TS are summarized in Table 1 . The protein fraction extracted from TP was highly rich in glutamic acid (16.38 $\pm 0.55 \%$ of total amino acid content), aspartic acid (11.41 $\pm 0.52 \%)$, serine (9.60 $\pm 0.34 \%)$, phenylalanine $(8.70 \pm 0.29 \%)$, and leucine $(7.01 \pm 0.37 \%)$. TP protein contained also alanine, tryptophan, and

Table 1 Total amino acid profile of the protein extracted from tomato peel and seed by-products

\begin{tabular}{|c|c|c|}
\hline & \multicolumn{2}{|c|}{ Amino acid (mg/g protein) } \\
\hline & TP & TS \\
\hline Aspartic acid & $114.1 \pm 5.2$ & $102.1 \pm 3.7$ \\
\hline Glutamic acid & $163.8 \pm 5.5$ & $214.2 \pm 0.7$ \\
\hline Asparagine & $16.9 \pm 1.2$ & 0.0 \\
\hline Serine & $96.0 \pm 3.4$ & $54.7 \pm 2.2$ \\
\hline Glutamine & 0.0 & $2.6 \pm 0.3$ \\
\hline Histidine $^{a}$ & $20.3 \pm 1.8$ & $26.1 \pm 0.8$ \\
\hline Glycine & $45.2 \pm 0.8$ & $55.2 \pm 3.4$ \\
\hline Threonine $^{a}$ & $35.0 \pm 4.2$ & $33.9 \pm 2.6$ \\
\hline Arginine & $44.1 \pm 3.4$ & $91.7 \pm 4.4$ \\
\hline Alanine & $56.5 \pm 3.1$ & $47.9 \pm 3.0$ \\
\hline Tyrosine & $27.1 \pm 0.4$ & $41.2 \pm 2.0$ \\
\hline$V_{\text {Valine }}^{\mathrm{a}}$ & $42.9 \pm 0.5$ & $52.1 \pm 3.9$ \\
\hline Methionine ${ }^{a}$ & $13.6 \pm 0.9$ & $18.8 \pm 4.1$ \\
\hline Tryptophan ${ }^{a}$ & $57.6 \pm 1.7$ & $17.2 \pm 0.6$ \\
\hline Phenylalanine ${ }^{a}$ & $87.0 \pm 2.9$ & $70.3 \pm 4.9$ \\
\hline Isoleucine ${ }^{a}$ & $56.5 \pm 1.3$ & $56.8 \pm 3.4$ \\
\hline Ornithine & $21.5 \pm 1.5$ & $2.6 \pm 0.5$ \\
\hline Leucine $^{a}$ & $70.1 \pm 3.7$ & $80.3 \pm 5.6$ \\
\hline Lysine $^{\mathrm{a}}$ & $31.6 \pm 2.5$ & $32.3 \pm 3.1$ \\
\hline
\end{tabular}

${ }^{a}$ Refers to essential amino acids isoleucine with values around $5 \%$ of the total protein content.

Similarly, TS protein was primarily rich in glutamic acid $(21.42 \pm 0.07 \%)$, aspartic acid $(10.21 \pm 0.37 \%)$, arginine $(9.17 \pm 0.44 \%)$, leucine $(8.03 \pm 0.56 \%)$, and phenylalanine $(7.03 \pm 0.49 \%)$. TS were also reported by Persia et al. [13] to be mostly rich in glutamic acid and aspartic acid. Quite comparable but lower amounts of serine, glycine, valine, and isoleucine were nearing $5 \%$ of the total TS protein. Unlike many other plant proteins, TP and TS are not deficient in lysine since they contained, respectively, $3.16 \pm 0.25$ and $3.23 \pm 0.31 \%$ lysine of the total amino acids. Overall, the essential amino acids, followed by superscript stars in Table 1, represented high proportions of the total amino acids, being equal to $41.46 \pm 0.19$ and $38.78 \pm 0.29 \%$, in TP and TS, respectively.

Besides, TP and TS were deemed to be endowed with good-quality proteins regarding the high scores for most of their essential amino acids as compared to those of a reference protein recognized for the nutrition of infants between 1 and 2 years old [36] (Table 2). Noticeably, tomato by-products are considerably rich in isoleucine, tryptophan, and aromatic amino acids (phenylalanine and tyrosine). Additionally, the protein efficiency ratio, PER, of TP was equal to 2.35 and that of TS was equal to 2.55. As any protein having PER higher than 2.50 is considered to be of high nutritional quality [11], the TS protein can be considered as a good-nutritional quality protein. The TP protein was endowed with a slightly lower quality than that of TS according to the PER rapid estimation. Sarkar and Kaul [11] found a comparable PER equal to 2.66 for TS protein.

\section{Liquid hot water hydrolysis}

The final step in the biorefinery cascade processing performed in the present study consisted of the LHW

Table 2 Amino acid scoring pattern of the protein extracted from tomato peel and seed by-products

\begin{tabular}{|c|c|c|c|c|c|}
\hline Amino acids & $\begin{array}{l}\text { Reference protein } \\
\text { (mg/g protein) [36] }\end{array}$ & $\begin{array}{l}\text { TP protein } \\
\text { (mg/g protein) }\end{array}$ & $\begin{array}{l}\text { TP amino acid score } \\
(\%)\end{array}$ & $\begin{array}{l}\text { TS protein } \\
\text { (mg/g protein) }\end{array}$ & $\begin{array}{l}\text { TS amino acid score } \\
(\%)\end{array}$ \\
\hline Histidine & $18.0 \pm 1.4$ & $20.3 \pm 1.8$ & $112.8 \pm 10.0$ & $26.1 \pm 0.8$ & $145.0 \pm 4.4$ \\
\hline Isoleucine & $31.0 \pm 0.7$ & $56.5 \pm 1.3$ & $182.3 \pm 4.2$ & $56.8 \pm 3.4$ & $183.2 \pm 11.0$ \\
\hline Leucine & $63.0 \pm 1.4$ & $70.1 \pm 3.7$ & $111.3 \pm 5.9$ & $80.3 \pm 5.6$ & $127.5 \pm 8.9$ \\
\hline Lysine & $52.0 \pm 2.8$ & $31.6 \pm 2.5$ & $60.8 \pm 4.8$ & $32.3 \pm 3.1$ & $62.1 \pm 6.0$ \\
\hline $\begin{array}{l}\text { Methionine } \\
\text { + cysteine }\end{array}$ & $25.0 \pm 0.7$ & $13.6 \pm 0.9$ & $54.4 \pm 3.6$ & $18.8 \pm 4.1$ & $75.2 \pm 16.4$ \\
\hline $\begin{array}{c}\text { Phenylalanine } \\
\text { + tyrosine }\end{array}$ & $46.0 \pm 3.5$ & $114.1 \pm 3.3$ & $248.0 \pm 7.2$ & $111.5 \pm 6.9$ & $242.4 \pm 15.0$ \\
\hline Threonine & $27.0 \pm 1.4$ & $35.0 \pm 4.2$ & $129.6 \pm 15.6$ & $33.9 \pm 2.6$ & $125.6 \pm 9.6$ \\
\hline Tryptophan & $7.0 \pm 0.3$ & $57.6 \pm 1.7$ & $822.9 \pm 24.3$ & $17.2 \pm 0.6$ & $245.7 \pm 8.6$ \\
\hline Valine & $41.0 \pm 0.7$ & $42.9 \pm 0.5$ & $104.6 \pm 1.2$ & $52.1 \pm 3.9$ & $127.1 \pm 9.6$ \\
\hline Essential amino acids & & $414.6 \pm 19.5$ & & $387.8 \pm 29.0$ & \\
\hline
\end{tabular}


treatment of TP and TS residues resulting from $\mathrm{SC}-\mathrm{CO}_{2}$ and protein extractions. For comparison, raw TP and TS were analyzed under the same operating conditions. According to fiber analysis, the lignocellulosic matter was the major fraction of TP and TS with the values equal to $67.40 \pm 2.15$ and $63.30 \pm 1.06 \%$ on dry basis, respectively. In fact, TP contained $18.50 \pm 0.13 \%$ of dry mass as cellulose, $6.0 \pm 0.04 \%$ hemicellulose, and $42.90 \pm 1.98 \%$ as total lignin, being the sum of acidsoluble lignin $(2.90 \pm 0.13 \%)$ and acid-insoluble lignin $(40.0 \pm 2.01 \%)$. TS contained $9.0 \pm 0.87 \%$ of dry mass as cellulose, $16.20 \pm 0.97 \%$ hemicellulose with mannose being the major sugar accounting for $11.20 \pm 0.66 \%$ of TS dry mass, and $38.1 \pm 0.78 \%$ as total lignin, where the acid-insoluble lignin was $31.0 \pm 0.86 \%$. Comparably, Navarro-González et al. [45] showed that the lignocellulosic matter was equal to $84.16 \%$ of TP fiber where the major fraction, the insoluble dietary fiber $(71.82 \%)$, was mainly formed by cellulose and hemicellulose. Besides, the neutral sugar composition of the lignocellulosic matter showed that the main sugars of TP fiber are mannose, galactose, xylose, and arabinose, which indicated that hemicelluloses were the predominant polysaccharides of this fiber. However, this study suggested limited content of lignin in TP fiber [45]. Likewise, Cepeda and Collado [46] showed that the lignocellulosic matter represented $65 \%$ of the total tomato fiber, where the soluble dietary fiber was $9 \%$ including a pectin content of $6 \%$ and the insoluble dietary fiber was $56 \%$ including a lignin content of $23 \%$.

\section{Liquid hot water hydrolysis of tomato peels}

LHW hydrolysis experiment consisted of submitting raw tomato peels (TP) and tomato peels previously submitted to carotenoid extraction using $\mathrm{SC}-\mathrm{CO}_{2}$ and protein extraction (PT-TP) to a batch LHW hydrolysis experiment. Pressurized hot water at 50 bar was used for the pretreatment of TP samples at 120,160 , and $200{ }^{\circ} \mathrm{C}$ for
$30 \mathrm{~min}$. The slurry was then centrifuged and separated into two parts: solid and liquid fractions that were analyzed for their fiber and sugar composition profiles. Yields mentioned in Table 3 are calculated as the percentages of the initial cellulose, hemicellulose, and lignin amounts contained in the starting material used for the LHW experiment.

Regarding the liquid fraction analysis shown in Table 3, it is noticeable that although being endowed with a more rigid structure than hemicellulose, cellulose was much more hydrolyzed from raw TP at 120 and $160{ }^{\circ} \mathrm{C}$. Actually, it is undeniable that assuming all the amount of glucose to account for cellulose remains a relative assumption since hemicellulose may always contain glucose [45]. Generally, the release of sugars from cellulose had been reported to begin at $200{ }^{\circ} \mathrm{C}$, whereas in the present study it seemed to occur at lower temperature. Likewise, the study by Mohan et al. [25] revealed that cellulose had undergone hydrolysis at $170{ }^{\circ} \mathrm{C}$. Comparable results were obtained by $\mathrm{Lu}$ and Saka [47] during their study on the hydrolysis of Japanese beech in a batch reactor at $170{ }^{\circ} \mathrm{C}$, whereas in a semi-batch reactor the hydrolysis temperature was around $210{ }^{\circ} \mathrm{C}$. Hence, from the study by Lu and Saka [47], it was deducible that a batch reactor configuration allows the use of low operating temperatures, giving a safe and economically favorable operation.

In addition, based on sugar analysis in the solid fractions, the degradation of cellulose seemed quite independent of temperature, while the degradation of hemicellulose increased with increasing temperature. Indeed, quite comparable yields of cellulose, $81.8 \pm 1.4$, $83.9 \pm 3.4$, and $79.41 \pm 3.3 \%$, were recovered in the solid fractions after LHW hydrolysis of raw TP at 120, 160 , and $200{ }^{\circ} \mathrm{C}$, respectively. Whereas $80.8 \pm 2.7 \%$ of hemicellulose was recovered in the solid fraction after LHW treatment of raw TP at $120^{\circ} \mathrm{C}$, only $68.5 \pm 3.0$ and $42.3 \pm 4.5 \%$ of hemicellulose were recovered after LHW

Table 3 Lignocellulosic component recovery in the liquid and solid fractions of LHW hydrolysates from tomato peels

\begin{tabular}{|c|c|c|c|c|c|c|c|c|}
\hline \multirow[t]{2}{*}{ Sample } & \multicolumn{3}{|c|}{$\begin{array}{l}\text { Component recovery in LHW liquid fraction } \\
\text { (\% of total component amount) }\end{array}$} & \multicolumn{4}{|c|}{$\begin{array}{l}\text { Component recovery in LHW solid fractions } \\
\text { (\% of total component amount) }\end{array}$} & \multirow[t]{2}{*}{ Weight loss (DW \%) } \\
\hline & Cellulose & Hemicellulose & $\begin{array}{l}\text { Sugar transforma- } \\
\text { tion by-products }\end{array}$ & Cellulose & Hemicellulose & Acid-soluble lignin & Total lignin & \\
\hline TP-120 & $34.9 \pm 4.2$ & 0 & $16.5 \pm 3.8$ & $81.8 \pm 1.4$ & $80.8 \pm 2.7$ & $71.4 \pm 3.6$ & $94.6 \pm 2.6$ & $21.9 \pm 1.8$ \\
\hline TP-160 & $32.9 \pm 3.0$ & $7.6 \pm 1.5$ & $17.2 \pm 2.0$ & $83.9 \pm 3.4$ & $68.5 \pm 3.0$ & $69.6 \pm 2.7$ & $100 \pm 5.4$ & $24.9 \pm 2.4$ \\
\hline TP-200 & $3.4 \pm 0.4$ & $11.5 \pm 2.4$ & $22.5 \pm 1.8$ & $79.4 \pm 3.3$ & $42.3 \pm 4.5$ & $69.2 \pm 0.8$ & $100 \pm 3.9$ & $31.5 \pm 0.9$ \\
\hline PT-TP-120 & $2.8 \pm 0.7$ & $1.9 \pm 0.6$ & $3.4 \pm 0.4$ & $75.2 \pm 1.0$ & $73.5 \pm 5.2$ & $36.0 \pm 3.6$ & $87.9 \pm 2.0$ & $9.1 \pm 4.1$ \\
\hline PT-TP-160 & $2.1 \pm 0.1$ & $8.9 \pm 1.5$ & $5.8 \pm 0.6$ & $62.3 \pm 1.6$ & $56.9 \pm 3.1$ & $19.4 \pm 1.8$ & $75.6 \pm 1.7$ & $25.8 \pm 1.3$ \\
\hline PT-TP-200 & $0.1 \pm 0.04$ & $2.4 \pm 0.6$ & $3.1 \pm 0.2$ & $67.3 \pm 3.1$ & $46.1 \pm 2.4$ & $20.7 \pm 1.1$ & $80.9 \pm 0.7$ & $22.9 \pm 0.6$ \\
\hline
\end{tabular}

DW dry weight 
treatment at 160 and $200{ }^{\circ} \mathrm{C}$, respectively. Comparable trends were noticed for the solubilization of cellulose and hemicellulose starting from PT-TP, mainly based on the analysis of the solid fractions, where the effect of temperature was more significant for the degradation of hemicellulose than for cellulose (Table 3).

After LHW hydrolysis of raw TP and PT-TP, the highest recovery yields of hemicellulose and cellulose sugars within the liquid fractions were achieved at a temperature not exceeding $160^{\circ} \mathrm{C}$. Overall, further increase of temperature to $200{ }^{\circ} \mathrm{C}$ led to a sharp decrease of hemicellulose and mainly cellulose recovery yields within the liquid fractions in favor for the formation of higher sugar degradation by-products from raw TP and PT-TP $[2,48]$. Hence, a temperature of $160^{\circ} \mathrm{C}$ was deduced to be the most convenient for better cellulose and hemicellulose hydrolysis with LHW treatment of raw TP and PT-TP while keeping the sugar transformation by-products low. Although the fraction of acid-soluble lignin was considerably dissolved during LHW hydrolysis of raw TP, $30.8 \pm 0.8 \%$ at $200{ }^{\circ} \mathrm{C}$, and PT-TP, $79.3 \pm 1.1 \%$ at $200{ }^{\circ} \mathrm{C}$, the acid-insoluble lignin was barely hydrolyzed. Indeed, about $75-100 \%$ of total lignin was recovered within the solid fractions after LHW hydrolysis of raw TP and PT-TP at different temperature levels. In the same vein, it is worth noting that the medium tended to be more acidic with increasing LHW temperature. Practically, increasing temperature promotes the liberation of acids from hemicellulose such as glucuronic acid and acetic acid, the sugar fermentation products such as lactic acid, and the sugar transformation products such as levulinic acid and formic acid [3]. Therefore, the acid-soluble lignin dissolved more sharply with the increase of the LHW temperature as compared to the acid-insoluble lignin.

\section{Liquid hot water hydrolysis of tomato seeds}

LHW was applied on raw TS and pretreated TS (PTTS) at the temperatures of 120,160 , and $200{ }^{\circ} \mathrm{C}$ and a pressure of 50 bar for $30 \mathrm{~min}$ of hydrolysis time. Based on sugar analysis of the liquid fractions from raw TS and PT-TS, it seemed that cellulose was much more hydrolyzed than hemicellulose at different temperatures (Table 4). As for TP, regarding the solid fractions of raw TS and PT-TS, the degradation of cellulose seemed to vary barely as a function of temperature, while hemicellulose degradation seemed to increase significantly with increasing temperature. This can be attributed to the fact that the hydrolysis capacity of water, in LHW treatment, increased with increasing temperature in the subcritical range $\left(\mathrm{P}<221\right.$ bar, $\left.\mathrm{T}<374{ }^{\circ} \mathrm{C}\right)$ [25]. Effectively, Cepeda and Collado [46] showed that the sterilization of a suspension of tomato fibers in water $(5 \%, \mathrm{w} / \mathrm{v})$ at $110{ }^{\circ} \mathrm{C}$ for $20 \mathrm{~min}$ led to a reduction in the insoluble dietary fiber content. This reduction could be attributed to partial degradation of cellulose, hemicellulose, and Klason lignin into simple carbohydrates as a consequence of heat treatment. Likewise, the transformation of sugars into other by-products seemed to increase with temperature (Table 4).

LHW hydrolysis results starting from raw TS were compared with those from PT-TS (Table 4). Less recovery yields of cellulose and hemicellulose were obtained in the PT-TS solid fractions as compared to those of raw TS. This is expected to reflect a better hydrolysis of the PT-TS samples and a better sugar recovery within the liquid hydrolysates. However, regarding the results of the relevant liquid fractions of PT-TS, there were low yields of cellulose and hemicellulose sugars. The overall balance of cellulose and hemicellulose recovered within the liquid and the solid fractions from the PT-TS is much less than $100 \%$. Then, it is noteworthy that, besides sugar degradation occurring during LHW hydrolysis, part of the sugars might have already been dissolved in the previous steps of pretreatment, more probably within the protein extraction step. In this context, Jiang et al. [48] suggested that part of the sugars might undergo a transformation

Table 4 Lignocellulosic component recovery in the liquid and solid fractions of LHW hydrolysates from tomato seeds

\begin{tabular}{|c|c|c|c|c|c|c|c|c|}
\hline \multirow[t]{2}{*}{ Sample } & \multicolumn{3}{|c|}{$\begin{array}{l}\text { Component recovery in LHW liquid fraction } \\
\text { (\% of total component amount) }\end{array}$} & \multicolumn{4}{|c|}{$\begin{array}{l}\text { Component recovery in LHW solid fractions } \\
\text { (\% of total component amount) }\end{array}$} & \multirow[t]{2}{*}{ Weight loss (DW \%) } \\
\hline & Cellulose & Hemicellulose & $\begin{array}{l}\text { Sugar transforma- } \\
\text { tion by-products }\end{array}$ & Cellulose & Hemicellulose & Acid-soluble lignin & Total lignin & \\
\hline TS-120 & $42.0 \pm 4.4$ & 0 & $5.7 \pm 0.5$ & $69.8 \pm 1.2$ & $90.2 \pm 3.7$ & $90.7 \pm 1.8$ & $81.9 \pm 3.2$ & $20.9 \pm 1.9$ \\
\hline TS-160 & $51.3 \pm 2.3$ & $1.5 \pm 0.2$ & $6.9 \pm 0.7$ & $75.9 \pm 2.6$ & $81.6 \pm 2.8$ & $68.2 \pm 5.2$ & $80.3 \pm 1.7$ & $32.1 \pm 2.5$ \\
\hline TS-200 & $15.5 \pm 3.8$ & 0 & $11.9 \pm 0.8$ & $65.4 \pm 3.4$ & $28.4 \pm 3.3$ & $26.7 \pm 3.6$ & $67.6 \pm 2.2$ & $56.9 \pm 0.8$ \\
\hline PT-TS-120 & 0 & $0.5 \pm 0.04$ & $2.4 \pm 0.3$ & $59.5 \pm 2.1$ & $81.5 \pm 0.9$ & $33.9 \pm 0.9$ & $31.9 \pm 4.1$ & $12.5 \pm 0.7$ \\
\hline PT-TS-160 & $4.9 \pm 0.7$ & $0.5 \pm 0.03$ & $2.3 \pm 0.2$ & $58.8 \pm 3.5$ & $69.2 \pm 2.1$ & $24.7 \pm 2.9$ & $28.7 \pm 2.6$ & $24.4 \pm 1.2$ \\
\hline PT-TS-200 & $11.3 \pm 1.6$ & 0 & $5.7 \pm 0.5$ & $58.2 \pm 4.3$ & $59.6 \pm 3.0$ & $8.8 \pm 3.4$ & $32.4 \pm 2.0$ & $34.6 \pm 1.6$ \\
\hline
\end{tabular}

DW dry weight 
into gaseous compounds with increasing temperature, resulting in the decreased amounts of hydrolyzed sugars within the liquid hydrolysates. This may have occurred in the present study, which may explain part of the loss of mass balance of cellulose and hemicellulose.

Furthermore, although lignin is well known for its very rigid structure, lignin polymers have undergone a degradation reaction as a function of temperature. Indeed, increasing the temperature from $120^{\circ} \mathrm{C}$ up to $200{ }^{\circ} \mathrm{C}$ led to the decreasing recovery yields of acid-soluble lignin from $90.7 \pm 1.8$ to $26.7 \pm 3.6 \%$ and of total lignin from $81.9 \pm 3.2$ to $67.6 \pm 2.2 \%$ within the solid fractions of raw TS, respectively. Comparably, lignin has also been observed by Jiang et al. [48] and Reddy et al. [27] to undergo solubilization reactions during LHW pretreatment of giant reed and sugarcane bagasse, respectively.

Overall, the total solubilization of TS samples using LHW process increased significantly with increasing temperature from $20.9 \pm 1.9 \%$ at $120{ }^{\circ} \mathrm{C}$ up to $56.9 \pm 0.8 \%$ at $200{ }^{\circ} \mathrm{C}$, on dry TS basis (Table 4). Similarly, starting from PT-TS, the total solubilization of dry pretreated samples was $12.5 \pm 0.7 \%$ at $120{ }^{\circ} \mathrm{C}$ and $34.6 \pm 1.6 \%$ at $200{ }^{\circ} \mathrm{C}$. The decrease of the solubilization yields of PT-TS after LHW as compared to that from raw TS can be attributed to the fact that an important fraction of the dry matter had already been removed or partially degraded within the $\mathrm{SC}-\mathrm{CO}_{2}$ and the protein extraction steps. Indeed, under the effect of heat and pressure during the LHW treatment of raw TS, protein is highly expected to dissolve within the liquid hydrolysates. Besides, despite the fact that oil is not highly extractable with water, some oil droplets were practically noticed within the liquid fractions of LHW slurries from raw TS.

To sum up, the highest recovery yields of hemicellulose and cellulose within the liquid fraction of raw TS after LHW were obtained at $160{ }^{\circ} \mathrm{C}$ with the values equal to $1.5 \pm 0.2$ and $51.3 \pm 2.3 \%$, respectively. Although a temperature of $200{ }^{\circ} \mathrm{C}$ was found to yield better cellulose hydrolysis from the PT-TS with a value of $11.3 \pm 1.6 \%$, a low operating temperature of $160{ }^{\circ} \mathrm{C}$ was similarly required for better hemicellulose hydrolysis with a value of $0.5 \pm 0.03 \%$. Further increase in the temperature to $200{ }^{\circ} \mathrm{C}$ tended to promote the degradation of the hydrolyzed sugars and their transformation to side by-products during the hydrolysis process (Table 4). Indeed, considering the LHW hydrolysis of raw TS and PT-TS, a temperature of $200{ }^{\circ} \mathrm{C}$ seemed to promote the transformation of the total hydrolyzed hemicellulose sugars to other by-products, with null hemicellulose sugars recovered within the liquid fractions, in both cases. Indeed, the study by Jiang et al. [48] revealed also that the increased amount of degradation products was consistent with the decrease of hemicellulose recovery efficiency. Thus, $160^{\circ} \mathrm{C}$ seemed to be the most convenient temperature for better cellulose and hemicellulose hydrolysis with LHW treatment of raw TS and PT-TS while keeping the sugar transformation by-products low. Quite comparable temperatures equal to 190 and $180{ }^{\circ} \mathrm{C}$ were deduced by $\mathrm{Lu}$ and Saka [47] and Mohan et al. [25] as optimum for the maximum sugar release within the LHW treatment of Japanese beech and bamboo, respectively.

\section{Comparison between TS and TP LHW hydrolysis}

The overall mass balance after LHW hydrolysis was better conserved for cellulose as compared to hemicellulose and for raw TP and TS as compared to PT-TP and PT-TS, respectively (Tables 3,4 ). This result was based on the sum of the yields of cellulose and hemicellulose between the liquid and solid fractions of the LHW hydrolysates, separately, from raw and pretreated tomato by-products.

Generally, LHW treatment is known to solubilize mainly the hemicellulose fraction of biomass [4]. Therefore, TS which contained much more hemicellulose tended to submit more hydrolysis as compared to TP. This fact was confirmed based on the total solubilization yields, expressed as weight losses in Tables 3 and 4. Effectively, LHW treatment at $200{ }^{\circ} \mathrm{C}$ resulted in the hydrolysis of $56.9 \pm 0.8 \%$ of raw TS and $34.6 \pm 1.6 \%$ of PT-TS, on dry basis, while only $31.5 \pm 0.9 \%$ of raw TP and $22.9 \pm 0.6 \%$ of PT-TP were solubilized at the same temperature. In the same line, the total lignin was much highly recovered in the solid residues of TP samples (raw TP and PT-TP) as compared to TS samples (raw TS and PT-TS). Hence, from this study it can be said that TP had a much more rigid lignocellulosic structure than TS, maybe because they have higher cellulose and lignin contents.

Although LHW treatment of PT-TP and PT-TS did not promote high yields of sugars within the liquid hydrolysates, as shown in Tables 3 and 4, LHW liquid fractions from raw TP and TS, treated specifically at $160{ }^{\circ} \mathrm{C}$, seemed to be more promising for valorization as a source of bioethanol production [26, 49]. Thus, an extensive techno-economical study would be of high interest to determine the feasibility of utilizing these industrial byproducts for ethanol production. Importantly, a compromise should be made between carotenoid, oil, and protein extractions and sugars hydrolysis. A supplementary enzymatic hydrolysis step might be efficient for improving the hydrolysis of sugars from cellulose and hemicellulose fractions of PT-TP and PT-TS $[4,37,48]$. Moreover, a flowthrough method can be investigated for the hydrolysis of tomato industrial by-products, as this reactor configuration had been considered superior to batch methods for the solubilization of biomass in LHW treatment [27]. One other possible perspective could be the use of acid- or 
base-catalyzed LHW treatment of tomato by-products as suggested by Del Campo et al. [20]. The recovered lignin within the solid fraction after LHW treatment can be assessed as a food additive regarding its dietary fiber advantages [6]. The present analytical results suggest further investigation of the same cascade biorefinery processing of TP and TS together, avoiding the sieving step, and the integration feasibility of all thermal separation processes in a kind of "one stop unit."

\section{Conclusions}

This paper suggested an innovative biorefinery concept producing high-value compounds from tomato industrial residues. The work aimed to integrate $\mathrm{SC}-\mathrm{CO}_{2}$ extraction of carotenoids and TSO, protein isolation from TP and TS, and LHW treatment of the residual biomass. Results indicated that tomato by-products are not only a green source of lycopene-rich oleoresin and TSO and of protein with good nutritional quality but also a potential feedstock for bioethanol production. As growing research has focused on LHW hydrolysis of lignocellulose for subsequent ethanol production, the present results would provide valuable practical experience regarding the hydrolysis of tomato industrial by-products.

\begin{abstract}
Abbreviations
TP: tomato peels; TS: tomato seeds; LHW: liquid hot water; SC- $\mathrm{CO}_{2}$ : supercritical $\mathrm{CO}_{2}$; SFE: supercritical fluid extraction; PER: protein efficiency ratio; HMF: hydroxymethylfurfural; TSO: tomato seed oil; PT-TP: pretreated TP: tomato peels previously submitted to oleoresin extraction using $\mathrm{SC}-\mathrm{CO}_{2}$ and protein batch extraction; PT-TS: pretreated TS: tomato seeds previously submitted to oil extraction using SC-CO and protein batch extraction; TP-120: TP submitted to LHW at $120^{\circ} \mathrm{C}$; PT-TP-120: PT-TP submitted to LHW at $120^{\circ} \mathrm{C} ; \mathrm{TS}-120$ : TS submitted to LHW at $120^{\circ} \mathrm{C}$; PT-TS-120: PT-TS submitted to LHW at $120^{\circ} \mathrm{C}$.
\end{abstract}

\section{Authors' contributions}

MK designed and performed the experiments, analyzed the data, and wrote the paper. LMS arranged for the analysis of the solid fractions after LHW hydrolysis, helped in data analysis, and critically reviewed the manuscript. WR participated in the design and execution of batch protein isolation and the LHW hydrolysis experiments and reviewed the manuscript. CZ helped in the design of the overall experiments, provided the experimental platform, and reviewed the manuscript. AZ kindly provided the tomato industrial byproducts. IS, NA, and SS coordinated this research project and gave the final approval for the manuscript to be published. All authors read and approved the final manuscript.

\section{Author details}

${ }_{1}^{1}$ Laboratory of Environmental Bioprocesses, Centre of Biotechnology of Sfax, University of Sfax, PO Box 1177, 3018 Sfax, Tunisia. ${ }^{2}$ Institute of Environmental Technology and Energy Economics, Hamburg University of Technology, Eißendorfer Straße 40, 21073 Hamburg, Germany. ${ }^{3}$ Institute of Thermal Separation Processes, Hamburg University of Technology, Eißendorfer Straße 38, 21073 Hamburg, Germany. ${ }^{4}$ Ayachi Group Industry, El Mansoura, 6131 Siliana, Tunisia. ${ }^{5}$ Laboratory of Chemistry of Natural Substances UR11-ES74, Faculty of Sciences of Sfax, University of Sfax, PO Box 1171, 3000 Sfax, Tunisia.

\section{Acknowledgements}

Special thanks are addressed to Mrs. Wassila Kehili for kindly helping in the separation of tomato peels and seeds with manual sieves and to Mr. Jörg Carstens and all the analysis staff of TUHH, Germany, for their kind service.

\section{Competing interests}

The authors declare that they have no competing interests.

\section{Availability of data and materials}

All data generated or analyzed during this study are included in this article.

\section{Funding}

This study was carried out as part of a MOBIDOC thesis funded by the European Union within the PASRI program administered by the "Agence Nationale de Promotion de la Recherche (ANPR). "This work was partially funded by the Ministry of Higher Education, Scientific Research and Technology, Tunisia.

Received: 21 September 2016 Accepted: 24 November 2016

Published online: 01 December 2016

\section{References}

1. Ishii J, Okazaki F, Djohan AC, Hara KY, Nakashima NA, Teramura H, et al. From mannan to bioethanol: cell surface co-display of $\beta$-mannanase and $\beta$-mannosidase on yeast Saccharomyces cerevisiae. Biotechnol Biofuels. 2016:188:1-15.

2. Kazan A, Celiktas MS, Sargin S, Yesil-Celiktas O. Bio-based fractions by hydrothermal treatment of olive pomace: process optimization and evaluation. Energy Convers Manag. 2015;103:366-73.

3. Wood IP, Cao HG, Tran L, Cook N, Ryden P, Wilson DR, et al. Comparison of saccharification and fermentation of steam exploded rice straw and rice husk. Biotechnol Biofuels. 2016;193:1-9.

4. Michelin M, Teixeira JA. Liquid hot water pretreatment of multi feedstocks and enzymatic hydrolysis of solids obtained thereof. Bioresour Technol. 2016:216:862-9.

5. Papaioannou EH, Karabelas AJ. Lycopene recovery from tomato peel under mild conditions assisted by enzymatic pre-treatment and nonionic surfactants. Acta Biochim Pol. 2012;59:71-4.

6. García Herrera P, Sánchez-Mata MC, Cámara M. Nutritional characterization of tomato fiber as a useful ingredient for food industry. Innov Food Sci Emerg Technol. 2010;11:707-11.

7. Schettini E, Santagata G, Malinconico M, Immirzi B, Scarascia Mugnozza G, Vox G. Recycled wastes of tomato and hemp fibres for biodegradable pots: physico-chemical characterization and field performance. Resour Conserv Recycl. 2013;70:9-19.

8. Toscano G, Pizzi A, Foppa Pedretti E, Rossini G, Ciceri G, Martignon G, Duca D. Torrefaction of tomato industry residues. Fuel. 2015;143:89-97.

9. Zuorro A, Lavecchia R, Medici F, Piga L. Enzyme-assisted production of tomato seed oil enriched with lycopene from tomato pomace. Food Bioprocess Technol. 2012:6:3499-509.

10. López-Cervantes J, Sánchez-Machado DI, Valenzuela-Sánchez KP, NúñezGastélum JA, Escárcega-Galaz AA, Rodríguez-Ramírez R. Effect of solvents and methods of stirring in extraction of lycopene, oleoresin and fatty acids from over-ripe tomato. Int J Food Sci Nutr. 2013;56:187-93.

11. Sarkar A, Kaul P. Evaluation of tomato processing by-products: a comparative study in a pilot scale setup. J Food Process Eng. 2014;37:299-307.

12. Müller L, Catalano A, Simone R, Cittadini A, Fröhlich K, Böhm V, et al. Antioxidant capacity of tomato seed oil in solution and its redox properties in cultured macrophages. J Agric Food Chem. 2013;61:346-54.

13. Persia ME, Parsons CM, Schang M, Azcona J. Nutritional evaluation of dried tomato seeds. Poult Sci. 2003;82:141-6.

14. Vági $E$, Simándi $B$, Vásárhelyiné KP, Daood H, Kéry Á, Doleschall F, et al. Supercritical carbon dioxide extraction of carotenoids, tocopherols and sitosterols from industrial tomato by-products. J Supercrit Fluids. 2007;40:218-26.

15. Demirbas A. Oil, micronutrient and heavy metal contents of tomatoes. Food Chem. 2010;118:504-7.

16. Egydio JA, Moraes ÂM, Rosa PTV. Supercritical fluid extraction of lycopene from tomato juice and characterization of its antioxidation activity. J Supercrit Fluids. 2010;54:159-64.

17. Machmudah S, Zakaria Winardi S, Sasaki M, Goto M, Kusumoto N, et al. Lycopene extraction from tomato peel by-product containing tomato seed using supercritical carbon dioxide. J Food Eng. 2012;108:290-6. 
18. Longo C, Leo L, Leone A. Carotenoids, fatty acid composition and heat stability of supercritical carbon dioxide-extracted-oleoresins. Int J Mol Sci. 2012;13:4233-54

19. Rossini G, Toscano G, Duca D, Corinaldesi F, Foppa Pedretti E, Riva G. Analysis of the characteristics of the tomato manufacturing residues finalized to the energy recovery. Biomass Bioenergy. 2013;51:177-82.

20. Del Campo I, Alegría I, Zazpe M, Echeverría M, Echeverría I. Diluted acid hydrolysis pretreatment of agri-food wastes for bioethanol production. Ind Crops Prod. 2006;24:214-21.

21. Sheng T, Zhao L, Gao LF, Liu WZ, Cui MH, Guo ZC, et al. Lignocellulosic saccharification by a newly isolated bacterium, Ruminiclostridium thermocellum M3 and cellular cellulase activities for high ratio of glucose to cellobiose. Biotechnol Biofuels. 2016;172:1-11.

22. Li HY, Chen X, Wang CZ, Sun SN, Sun RC. Evaluation of the two-step treatment with ionic liquids and alkali for enhancing enzymatic hydrolysis of Eucalyptus: chemical and anatomical changes. Biotechnol Biofuels. 2016;166:1-13.

23. Parthasarathi R, Sun J, Dutta T, Sun N, Pattathil S, Konda NVSNM, et al. Activation of lignocellulosic biomass for higher sugar yields using aqueous ionic liquid at low severity process conditions. Biotechnol Biofuels. 2016;160:1-13.

24. Mattam AJ, Kuila A, Suralikerimath N, Choudary N, Rao PVC, Velankar HR. Cellulolytic enzyme expression and simultaneous conversion of lignocellulosic sugars into ethanol and xylitol by a new Candida tropicalis strain. Biotechnol Biofuels. 2016;157:1-12.

25. Mohan M, Banerjee T, Goud W. Hydrolysis of bamboo biomass by subcritical water treatment. Bioresour Technol. 2015;191:244-52.

26. Jiang W, Chang S, Li H, Oleskowicz-Popiel P, Xu J. Liquid hot water pretreatment on different parts of cotton stalk to facilitate ethanol production. Bioresour Technol. 2015;176:175-80.

27. Reddy P, Lekha P, Reynolds W, Kirsch C. Structural characterisation of pretreated solids from flow-through liquid hot water treatment of sugarcane bagasse in a fixed-bed reactor. Bioresour Technol. 2015;183:259-61.

28. Scoma A, Rebecchi S, Bertin L, Fava F. High impact biowastes from South European agro-industries as feedstock for second-generation biorefineries. Crit Rev Biotechnol. 2015;36:175-89.

29. Vardanega R, Prado JM, Meireles MAA. Adding value to agri-food residues by means of supercritical technology. J Supercrit Fluids. 2015;96:217-27.

30. Dickinson NL, Meyers JM. Solexol fractionation of menhaden oil. J Am Oil Chem Soc. 1952;29(6):235-9.

31. Gearhart JA, Garwin L. ROSE process improves resid feed. Hydrocarbon Process. 1976:55:125-8.

32. Brunner G. Counter-current separations. J Supercrit Fluids. 2009:47:574-82

33. Gairola K. Prozessintegrierte Wertstoffgerwinnung aus protein- und lignocellulosereichen Reststoffen "Process integrated recovery of valuable compounds from protein and lignocellulose rich residues". Hamburg: Hamburg University of Technology; 2013 (PhD Thesis)
34. Gairola K, Smirnova I. Hydrothermal pentose to furfural conversion and simultaneous extraction with $\mathrm{SC}-\mathrm{CO}_{2}$ - kinetics and application to biomass hydrolysates. Bioresour Technol. 2012;123:592-8.

35. Roh MK, Jeon MH, Moon JN, Moon WS, Park SM, Choi JS. A simple method for the isolation of lycopene from Lycopersicon esculentum. Bot Sci. 2013;91(2):187-92.

36. WHO/FAO/UNU. Protein and amino acid requirements in human nutrition. Report of a Joint WHO/FAO/UNU Expert Consultation. WHO Technical Report Series. 935. Geneva: World Health Organization; 2007.

37. Reynolds W, Kirsch C, Smirnova I. Thermal-enzymatic hydrolysis of wheat straw in a single high pressure fixed bed. Chem Ing Tech. 2015;87:1305-12

38. Celiktas MS, Kirsch C, Smirnova I. Cascade processing of wheat bran through a biorefinery approach. Energy Convers Manag. 2014;84:633-9.

39. Eller FJ, Moser JK, Kenar JA, Taylor SL. Extraction and analysis of tomato seed oil. J Am Oil Chem Soc. 2010;87:755-62.

40. Strati IF, Oreopoulou V. Process optimisation for recovery of carotenoids from tomato waste. Food Chem. 2011;129:747-52.

41. Prado JM, Veggi PC, Meireles MAA. Extraction methods for obtaining carotenoids from vegetables_review. Curr Anal Chem. 2014;10:29-66.

42. Baysal T, Ersus $\mathrm{S}$, Starmans DAJ. Supercritical $\mathrm{CO}_{2}$ extraction of $\beta$-carotene and lycopene from tomato paste waste. J Agric Food Chem. 2000;48:5507-11.

43. Del Valle JM, De la Fuente JC, Cardarelli DA. Contributions to supercritical extraction of vegetable substrates in Latin America. J Food Eng. 2005:67:35-57.

44. Zhang C, Sanders JPM, Bruins ME. Critical parameters in cost-effective alkaline extraction for high protein yield from leaves. Biomass Bioenergy. 2014;67:466-72.

45. Navarro-González I, García-Valverde V, García-Alonso J, Periago MJ. Chemical profile, functional and antioxidant properties of tomato peel fiber. Food Res Int. 2011;44:1528-35.

46. Cepeda E, Collado I. Rheology of tomato and wheat dietary fibers in water and in suspensions of pimento purée. J Food Eng. 2014;134:67-73.

47. Lu X, Saka S. Hydrolysis of Japanese beech by batch and semi-flow water under subcritical temperatures and pressures. Biomass Bioenergy. 2010:34:1089-97.

48. Jiang D, Ge X, Zhang Q, Li Y. Comparison of liquid hot water and alkaline pretreatments of giant reed for improved enzymatic digestibility and biogas energy production. Bioresour Technol. 2016;216:60-8.

49. Imman S, Arnthong J, Burapatana V, Champreda V, Laosiripojana N. Effects of acid and alkali promoters on compressed liquid hot water pretreatment of rice straw. Bioresour Technol. 2014;171:29-36.

\section{Submit your next manuscript to BioMed Central and we will help you at every step:}

- We accept pre-submission inquiries

- Our selector tool helps you to find the most relevant journal

- We provide round the clock customer support

- Convenient online submission

- Thorough peer review

- Inclusion in PubMed and all major indexing services

- Maximum visibility for your research

Submit your manuscript at www.biomedcentral.com/submit 